\section{RICYDE. Revista Internacional de Ciencias del Deporte doi: $10.5232 /$ ricyde \\ Rev. Int. cienc. deporte}

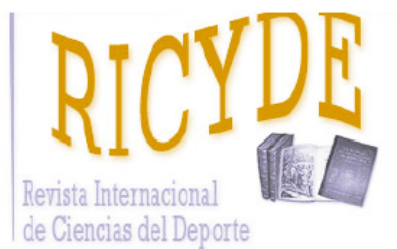

RICYDE. Revista Internacional de Ciencias del Deporte Volume XV - Year XV

Pages: $339-352$ - ISSN: $1885-3137$

Issue 58 - October 2019

https://doi.org/10.5232/ricyde2019.05803

\title{
Comparison of the physical and physiological demands of friendly matches and different types of preseason training sessions in professional soccer players \\ Comparación de las demandas físicas y fisiológicas entre partidos amistosos y diferentes sesiones de entrenamiento del periodo preparatorio en futbolistas profesionales
}

\section{Miguel Ángel Campos-Vázquez ${ }^{1}$, Julen Castellano ${ }^{2}$, Francisco Javier Toscano-Bendala ${ }^{3}$, Adam Owen ${ }^{4}$}

1.Universidad Pablo de Olavide (Sevilla). Spain

2.Universidad del País Vasco (UPV-EHU). Spain

3.Universidad Católica de Murcia (UCAM). Spain

4.Centre de Recherche et d'Innovation sur le Sport, Université Claude Bernard Lyon.1, Lyon. France

\section{Abstract}

The aim of this study was to compare the physical and physiological demands of friendly matches (FM) with different types of standard training sessions (TRs) undertaken by professional soccer players. Maximal velocity (MV), relative distance $(\mathrm{m} / \mathrm{min})$, distance covered in different high velocity and acceleration-deceleration zones, player load, repeated high intensity efforts and Edwards' TRIMP were assessed in 15 professional Spanish soccer players across the preseason period. Training sessions were classified under: tactical, pre-match activation, fitness-reserves and fitness sessions. Differences between FM and TRs, were analyzed for practical significance using magnitude-based inferences. MV and relative distance were substantially higher in FM than in tactical sessions (effect size, ES=1.69, large and 3.73 , very large), activation sessions ( $E S=2.07$, very large and 2.30 , very large), fitness-reserves sessions $(E S=2.85$, very large and 4.47 , very large) and fitness sessions ( $E S=2.30$, very large and 6.30 , very large) respectively. No substantial differences were observed in distance covered in high acceleration zone $(>3 \mathrm{~m} \cdot \mathrm{s}-2)$ between FM and activation, fitness-reserves and fitness sessions. TRIMPs obtained during FM were substantially higher than in tactical $(E S=5.37$, very large), activation $(E S=5.03$, very large), fitness-reserves ( $E S=3.82$, very large) and fitness sessions ( $E S=5.61$, very large). It can be concluded from this study that FMs produce the highest loaded training stimulus when compared across most metrics used for training analysis comparisons across the preseason period. As a result the use of FMs within the pre-season phase of the season should warrant additional care when planned between high intensity and high volume training loads.

Key words: GPS, heart rate; quantification; football; preseason.

\section{Resumen}

El objetivo de esta investigación fue comparar las demandas físicas y fisiológicas de partidos amistosos (PA), con las derivadas de diferentes tipos de sesiones de entrenamiento (TRs) realizadas por futbolistas profesionales. 15 futbolistas profesionales españoles fueron monitorizados en pretemporada en las siguientes variables: velocidad máxima (VM), distancia relativa $(\mathrm{m} / \mathrm{min})$, distancia recorrida en diferentes zonas de velocidad y aceleración, secuencias de alta intensidad repetidas, player load y TRIMP Edwards. Las TRs fueron clasificadas en: tácticas, activación pre-partido, condición física de jugadores reservas y condición física. Se evaluaron las diferencias entre PA y TRs a través de inferencias basadas en magnitudes. La VM y la distancia relativa fueron substancialmente mayores en PA que en la sesiones tácticas (tamaño del efecto, $T E=1.69$, grande y 3.73 , muy grande), sesiones activación ( $T E=2.07$, muy grande y 2.30 , muy grande), condición física-reservas $(T E=2.85$, muy grande y 4.47 , muy grande) y condición física ( $T E=2.30$, muy grande y 6.30 , muy grande) respectivamente. No se observaron diferencias substanciales en la distancia recorrida a alta aceleración $(>3 \mathrm{~m} \cdot \mathrm{s}-2)$ entre PA y sesiones activación, condición física y condición física-reservas. Sin embargo, los TRIMPs obtenidos durante PA fueron substancialmente mayores que en las sesiones tácticas ( $T E=5.27$, muy grande), activación ( $T E=5.03$, muy grande), condición física-reservas ( $\mathrm{TE}=3.82$, muy grande), y condición física ( $\mathrm{CV}=5.61$, muy grande). Como conclusión, los PA constituyen el estímulo de entrenamiento con mayor sobrecarga de la pretemporada, para la mayoría de variables analizadas. Por lo tanto se debería prestar especial atención, cuando se juegan PA en pretemporada intercalados entre sesiones de alta intensidad y alto volumen.

Palabras clave: GPS; frecuencia cardíaca; cuantificación; fútbol; pretemporada.

Correspondence/correspondencia: Miguel Ángel Campos-Vázquez

Pablo de Olavide University (Sevilla). Spain

Email: camposvazquez@hotmail.com 
Campos-Vázquez, M.; Castellano, J.; Toscano-Bendala, F. J., \& Owen, A. (2019). Comparison of the physical and physiological demands of friendly matches and different types of preseason training sessions in professional soccer players. RICYDE. Revista internacional de ciencias del deporte. 58(15), 339-352.

https://doi.org/10.5232/ricyde2019.05803

\section{Introduction}

Competitive soccer at the elite level requires players that are capable of mastering technical and tactical skills of the game under large physical stressors (Lago-Peñas, Lago-Ballesteros, Dellal, \& Gomez, 2010). Thus, soccer players need to achieve high physical fitness level through rigorous training structures (Iaia, Rampinini, \& Bangsbo, 2009). Furthermore, the physical conditioning levels of the players has hugely improved over recent years, and as a result of this, there has been an increased match physical demand imposed (Bush, Barnes, Archer, Hogg, \& Bradley, 2015). Attaining high levels of physical performance in soccer, specific development across a range of physical qualities such as strength, speed, and endurance is crucial (Desgorces, Senegas, Garcia, Decker, \& Noirez, 2007) in order to satisfy the physical and physiological demands of competition.

Analysis of the demands of competition is the only feasible way to establish the determinants of the physical conditioning necessary to reach a high level of physical performance at the elite level. As a result, numerous investigations in recent times have been discussed and published assessing movement patterns that occur during elite level soccer match-play (Di Salvo et al., 2007; Di Salvo, Gregson, Atkinson, Tordoff, \& Drust, 2009; Suarez-Arrones et al., 2015). Findings from these studies, have shown during competitive matches there are periods in which the intensity and the duration vary intermittently, resulting in frequent periods of high- intensity activity interspersed with low intensity periods. Also, in this dynamic of intermittent and random efforts, there are phases during games of which high demand actions accumulate with little recovery. These are the most intense phases in the game (Varley, Elias, \& Aughey, 2012).

Concerns from training periods is to know if the demands of competition are replicated during training sessions (TRs) in order to achieve match demands. As a result, coaches might try to manipulate a combination of factors such as volume and intensity (training load) (Malone, Di Michele, Morgans, Burgess, Morton, \& Drust, 2015) during TRs in order to manufacture competitive load. In soccer, training load (TL) is usually divided into two separate subsections: external TL (physical stimuli performed) and internal TL (physiological stress) (Scott, Lockie, Knight, Clark, \& Janse de Jonge, 2013). Sessions should be designed to replicate as close as possible to the external and internal TL achieved in games depending on the periodisation strategy implemented (Owen, Djaoui, Newton, Malone, \& Mendes, 2017), as previous literature suggests that performances may improve when training simulates the physiological demands and movement patterns of competitive matches (Sampaio, Abrantes, \& Leite, 2009). Previous investigations have analysed the differences between the physical demands in TRs and those in official matches (Scott et al., 2014) or friendly matches (FMs) (Casamichana \& Castellano, 2011), resulting physical demands higher during competition. However, these investigations did not discriminate between differences in the types of sessions, which could have influenced such results.

Due to the variety of conditional components usually present in TRs, such as endurance, speed, strength, power, and agility (Silva, Nassis, \& Rebelo, 2015), the orientation of these sessions might be different. Previous research has classified the type of TR in relation to the main objective of the session (Jeong, Reilly, Morton, Bae, \& Drust, 2011), to content covered during the TR (Campos-Vazquez et al., 2015), or to the location of the session in the microcycle structure (Coutinho et al., 2015). Due to the variety of sessions commonly used by soccer coaches, it could be interesting to know the values of external and internal TL supported in each type of session, with the aim of knowing their relationship with the values demanded by competition. Furthermore, such information might be used by coaches to design 
Campos-Vázquez, M.; Castellano, J.; Toscano-Bendala, F. J., \& Owen, A. (2019). Comparison of the physical and physiological demands of friendly matches and different types of preseason training sessions in professional soccer players. RICYDE. Revista internacional de ciencias del deporte. 58(15), 339-352.

https://doi.org/10.5232/ricyde2019.05803

different microcycles to propose the appropriate load for each TR, allowing players to achieve optimal performance during competition.

To date, no published studies have analyzed differences between the physical and physiological demands of friendly matches and the different types of TRs in professional soccer. As a result, the aim of this study was to compare the physical and physiological demands of friendly matches with different training session classifications normally reported within the literature and performed by professional players.

\section{Methods}

Participants

Twenty-two $(n=22)$ professional soccer players participated in this study (mean \pm SD: age $28.1 \pm 4.7$ years; height: $179.7 \pm 4.1 \mathrm{~cm}$; weight: $78.2 \pm 7.2 \mathrm{~kg}$; sum of 6 skinfolds: $51.0 \pm$ 8.6; \% fat [Faulkner]: $12.1 \pm 1.6)$. However, the sample was reduced to 15 players (6 defenders, 5 midfielders, and 4 forwards), since 7 players did not participate in the FMs, failing to deliver the results necessary to make the comparisons between different types of TR conditions. All players belonged to the same team, competing in 'Liga BBVA' (Spanish 1st Division, Season 2015-2016). All subjects were previously informed about the purpose, risks and benefits of the study and the types of tests they would be submitted to, and they gave their informed consent as directed by the Declaration of Helsinki. The study was approved by the Research Ethics Committee of Pablo de Olavide University.

\section{Procedures}

In this study, a descriptive design was used. The study was conducted over a full preseason and lasted seven weeks (July-August 2015). During this period, players performed five to nine TRs and played between one and two FMs each week. After the first week, a 1-week training camp was organized, during which the team alternated two-a-day TRs (morning and evening) with single TR a day (morning) or FM (evening). During the training camp, the dietary regime was strictly monitored by a nutritionist.

Throughout the preseason, the total time of each TR and FM was recorded for each player (including the warm-up and pauses). TRs had an average duration of $\sim 75$ minutes (range 60 to 90 minutes), whereas the participation of players in the FMs ranged between 95 and 120 minutes, depending on the criteria of the coach. The individual records of the players who did not complete any TR (by injury) were excluded from the analysis. In addition, the only individual records included in the analysis of the FMs were of players who played more than 65 minutes (full first half and at least 20 minutes of the second half). All the FMs were played in the evening, against same or higher competitive level teams. The formation used by the team in all monitored FMs was 1-5-3-2, i.e. a goalkeeper, 5 defenders, 3 midfielders, and 2 forwards.

\section{Training sessions:}

The TRs were grouped into different types depending on the objective, the time until the match, and the content developed in each session, defining the following types of TRs (Campos-Vazquez \& Toscano-Bendala, 2018):

- Tactical sessions (TAC). After the warm-up, an activation task played in a small space was performed. Subsequently, various conditioned tasks with an 11 vs. 11 setup played in moderately large areas ( 70 x $65 \mathrm{~m}$, length and width, respectively) were performed to improve the team model of gameplay. 
Campos-Vázquez, M.; Castellano, J.; Toscano-Bendala, F. J., \& Owen, A. (2019). Comparison of the physical and physiological demands of friendly matches and different types of preseason training sessions in professional soccer players. RICYDE. Revista internacional de ciencias del deporte. 58(15), 339-352.

https://doi.org/10.5232/ricyde2019.05803

- Fitness sessions (FIT). These sessions usually started with 30 to 45 minutes of general or functional strength training (i.e. full squat, take-offs with resisted sled towing, displacements with loads with change of direction, CORE stability training). After that, fitness tasks such as high-intensity interval training (HIIT), conditioning-technical circuits, or small-sided games (SSGs) were performed.

- Pre-match activation sessions (ACTV). These sessions were held prior to FM day. After the warm-up period, finishing actions executed at maximum velocity were performed. Then, players performed 15 to 20 minutes of an 11 vs. 11 match played on a $70 \times 65 \mathrm{~m}$ area. The session typically ended with 15 minutes of set pieces.

- Fitness reserves sessions (FIT-RES). This type of session was performed the day after the FM for players who did not participate or who played $<45$ minutes in the FM. After the warm-up period, players performed at high intensity, 6 to 12 repetitions of 15 to 30 seconds of explosive actions (accelerations, changes of direction, jumps) combined with technical skills. The session ended with SSGs with goals and goalkeepers. SSGs were organized as 5 vs. 5 on an individual area ranging from 90 to $120 \mathrm{~m}^{2}$ per player. Four sets of 4 to 5 minutes with recovery periods of 2 minutes were performed.

The average duration, the number of monitored sessions, and the number of individual records for each type of TR and FM are shown in Table 1.

Table 1. Volume and frequency of training sessions and friendly matches

\begin{tabular}{cccc}
\hline Session type & $\begin{array}{c}\text { Session duration in min } \\
(\text { mean } \pm \text { sd })\end{array}$ & $\begin{array}{c}\text { Number of sessions } \\
\text { monitored (range) }\end{array}$ & $\begin{array}{c}\text { Number of individual } \\
\text { records }\end{array}$ \\
\hline TAC & $72.4 \pm 8.0$ & $5(2-5)$ & 60 \\
FIT & $82.5 \pm 5.5$ & $7(2-7)$ & 76 \\
FIT-RES & $77.9 \pm 6.9$ & $5(0-5)$ & 20 \\
ACTV & $73.7 \pm 10.8$ & $4(2-4)$ & 54 \\
FM & $110.5 \pm 12.2$ & $5(2-5)$ & 46 \\
\hline TOTAL & 26 & 256 \\
\hline TAC: tactical sessions; FIT: fitness sessions; FIT-RES: reserves fitness sessions; ACTV: pre-match \\
activation sessions; FM: friendly matches
\end{tabular}

\section{Measures:}

During the first week, anthropometric assessments were performed, and the intermittent endurance performance was evaluated in the 30-15 Intermittent Fitness Test (30-15 IFT) (Buchheit, 2008). During the test, the players' maximum heart rate $\left(\mathrm{HR}_{\max }\right)$ was obtained (Buchheit, 2008). In players whose HRs were higher in the course of the TRs or FMs than the $\mathrm{HR}_{\max }$ obtained in the test, those new values were retained and used in the analysis.

Players were monitored using global positioning system (GPS) devices and heart rate bands in each TR and FM. The GPS device used (Minimax S4, Catapult Innovations, Melbourne, Australia) operates at a sampling frequency of $10 \mathrm{~Hz}$. This device has shown to have acceptable reliability and validity to estimate accelerations and sprints usually carried out while competing in team sports (Akenhead, French, Thompson, \& Hayes, 2014; Castellano, Casamichana, Calleja-Gonzalez, Roman, \& Ostojic, 2011; Varley, Fairweather, \& Aughey, 2012). To limit inter-unit error, each player wore the same unit throughout the full preseason. 
Campos-Vázquez, M.; Castellano, J.; Toscano-Bendala, F. J., \& Owen, A. (2019). Comparison of the physical and physiological demands of friendly matches and different types of preseason training sessions in professional soccer players. RICYDE. Revista internacional de ciencias del deporte. 58(15), 339-352.

https://doi.org/10.5232/ricyde2019.05803

The HR of each player was also monitored by HR bands (Polar® T-34, Kempele, Finland). All data were analysed with Openfield software v.1.10.0. (Catapult ${ }^{\circledR}$, Canberra).

Internal training load (ITL):

The ITL calculation was performed as proposed by Edwards (Edwards, 1993), using Edward's-TL indicator, integrating the total volume and training intensity, given five zones of intensity used. The calculation for each TR or FM was performed by multiplying the cumulative duration in each HR zone $(\mathrm{min})$ by a value assigned to each intensity zone $(90$ $100 \% \mathrm{HR}_{\max }=5 ; 80-90 \% \mathrm{HR}_{\max }=4 ; 70-80 \% \mathrm{HR}_{\max }=3 ; 60-70 \% \mathrm{HR}_{\max }=2 ; 50-60 \%$ $\left.\mathrm{HR}_{\max }=1\right)$ and then adding the results. Thus, it should be noted that Edward's-TL is measured in arbitrary units.

\section{External training load (ETL):}

The external load was assessed by considering the following variables: maximal velocity (MV), total distance covered per minute (TD), high intensity distance per minute (HID: > $14.4 \mathrm{~km} \cdot \mathrm{h}^{-1}$ ), very high intensity distance per minute (VHID: $>19.8 \mathrm{~km} \cdot \mathrm{h}^{-1}$ ), and sprint distance per minute (SP: $>25.2 \mathrm{~km} \cdot \mathrm{h}^{-1}$ ), all similar to the previously used variables (Rampinini, Coutts, Castagna, Sassi, \& Impellizzeri, 2007). Player load (PL) was also included (Casamichana, Castellano, \& Castagna, 2012; Montgomery, Pyne, \& Minahan, 2010) and obtained via an accelerometer, combining the accelerations in the three planes of movement of the body through a triaxial accelerometer $100 \mathrm{~Hz}$, and measured in arbitrary units. The variable was again relativised by the minute of the practice PL per minute (PL/min).

The following acceleration thresholds were established: moderate decelerations (MD; -2 to -3 $\mathrm{m} \cdot \mathrm{s}^{-2}$ ) and high decelerations (HD; $<-3 \mathrm{~m} \cdot \mathrm{s}^{-2}$ ) and moderate accelerations (MA; 2 to $3 \mathrm{~m} \cdot \mathrm{s}^{-2}$ ) and high accelerations (HA; $>3 \mathrm{~m} \cdot \mathrm{s}^{-2}$ ), as previously proposed (Osgnach, Poser, Bernardini, Rinaldo, \& di Prampero, 2010). The total distance covered for each category was calculated. In order to assess the most intense phases of TRs and FMs, the variable 'repeated highintensity effort' (RHIE), defined as the achievement of at least three efforts ( $\geq 1$ second) at a higher velocity of $14.4 \mathrm{~km} / \mathrm{h}$ or acceleration-deceleration $>3 \mathrm{~m} \cdot \mathrm{s}^{-2} /<-3 \mathrm{~m} \cdot \mathrm{s}^{-2}$ with a maximum recovery of 21 seconds, was used, as previously (Casamichana, et al., 2012). Because all sessions were not the same duration, all values of acceleration and RHIE were relativised to an hour of practice to make comparisons between the different types of TRs and FMs.

\section{Statistical Analysis}

The results are presented as mean \pm standard deviation (SD). In addition to the analysis for statistical significance, possible differences in internal and external load variables between FMs and the different types of TRs, were analyzed for practical significance using magnitudebased inferences (Hopkins, 2006). The data were log-transformed before analysis to reduce non uniformity of error. The effect size (ES) was determined, and the threshold values for Cohen ES statistics were trivial (0.0-0.19), small (0.2-0.59), moderate (0.6-1.1), large (1.21.9), and very large (>2.0) (Batterham \& Hopkins, 2006; Hopkins, Marshall, Batterham, \& Hanin, 2009). Probabilities were also calculated to establish whether the true (unknown) differences were lower, similar or higher than the smallest worthwhile difference or change ( 0.2 multiplied by the between-subject SD, based on Cohen's effect size principle). The qualitative descriptors proposed by Batterham \& Hopkins (2006) were used to interpret the likelihood that the true effect can be harmful, beneficial or trivial: $<1 \%$, almost certainly not; $<5 \%$, very unlikely; $<25 \%$, unlikely/probably not; $25 \%$ to $75 \%$, possibly/possibly not; $>75 \%$, 
Campos-Vázquez, M.; Castellano, J.; Toscano-Bendala, F. J., \& Owen, A. (2019). Comparison of the physical and physiological demands of friendly matches and different types of preseason training sessions in professional soccer players. RICYDE. Revista internacional de ciencias del deporte. 58(15), 339-352.

https://doi.org/10.5232/ricyde2019.05803

likely/probably; $>95 \%$, very likely; $>99 \%$, almost certainly. If the chance of having higher or lower values than the smallest worthwhile difference were both $>5 \%$, the true difference was assessed as unclear. A substantial effect was set at $>75 \%$ (Aughey, 2011; Campos-Vazquez, et al., 2015; Suarez-Arrones et al., 2014).

\section{Results}

The players' averaged values for each type of session and each of the variables are presented in Table 2.

Table 2. Comparison of physical and physiological demands between FMs and different types of TRs (mean $\pm \mathrm{SD})$

\begin{tabular}{|c|c|c|c|c|c|}
\hline & FM & TAC & ACTV & FIT-RES & FIT \\
\hline $\mathbf{M V}\left(\mathrm{km} \cdot \mathrm{h}^{-1}\right)$ & $29.3 \pm 1.6$ & $26.6 \pm 1.7 *$ & $26.0 \pm 1.9 *$ & $24.8 \pm 1.6^{*}$ & $25.7 \pm 1.9 *$ \\
\hline $\mathbf{T D}\left(\mathrm{m} \cdot \mathrm{min}^{-1}\right)$ & $93.7 \pm 7.4$ & $68.6 \pm 6.3^{*}$ & $77.3 \pm 6.7^{*}$ & $63.5 \pm 4.6^{*}$ & $56.6 \pm 5.4^{*}$ \\
\hline HID $\left(\mathrm{m} \cdot \mathrm{min}^{-1}\right)$ & $16.8 \pm 5.1$ & $9.1 \pm 2.8^{*}$ & $7.5 \pm 2.3 *$ & $7.9 \pm 2.2 *$ & $9.7 \pm 1.9^{*}$ \\
\hline VHID $\left(\mathrm{m} \cdot \mathrm{min}^{-1}\right)$ & $4.3 \pm 1.6$ & $2.0 \pm 1.0 *$ & $1.8 \pm 0.7^{*}$ & $1.4 \pm 0.9 *$ & $3.4 \pm 1.3^{*}$ \\
\hline $\mathbf{S P}\left(\mathrm{m} \cdot \mathrm{min}^{-1}\right)$ & $0.7 \pm 0.4$ & $0.3 \pm 0.2 *$ & $0.2 \pm 0.2 *$ & $0.2 \pm 0.2 *$ & $0.5 \pm 0.6^{*}$ \\
\hline PL $\left(\mathrm{AU} \cdot \mathrm{min}^{-1}\right)$ & $9 \pm 1.2$ & $7.0 \pm 1.0 *$ & $6.5 \pm 0.9 *$ & $7.0 \pm 0.8^{*}$ & $6.1 \pm 1.0^{*}$ \\
\hline RHIE (no hour $^{-1}$ ) & $11.7 \pm 4.6$ & $5.9 \pm 2.7 *$ & $5.2 \pm 2.3 *$ & $5.8 \pm 1.3 *$ & $5.4 \pm 2.6^{*}$ \\
\hline DHD $\left(\mathrm{m} \cdot\right.$ hour $\left.^{-1}\right)$ & $8.5 \pm 3.1$ & $4.9 \pm 2.6^{*}$ & $4.6 \pm 2.3^{*}$ & $3.2 \pm 1.3 *$ & $5.8 \pm 4.0^{*}$ \\
\hline DMD $\left(m \cdot\right.$ hour $\left.^{-1}\right)$ & $46 \pm 12.0$ & $28.0 \pm 8.8^{*}$ & $27.7 \pm 7.5^{*}$ & $27.2 \pm 5.4^{*}$ & $27.7 \pm 9.5^{*}$ \\
\hline DMA $\left(\mathrm{m} \cdot\right.$ hour $\left.^{-1}\right)$ & $106.6 \pm 21.8$ & $84.5 \pm 23.6^{*}$ & $96.3 \pm 25.8 *$ & $103.2 \pm 21.7$ & $91.2 \pm 24.8^{*}$ \\
\hline DHA $\left(\mathrm{m} \cdot\right.$ hour $\left.^{-1}\right)$ & $9.4 \pm 4.5$ & $4.6 \pm 2.9^{*}$ & $9.0 \pm 4.7$ & $7.3 \pm 3.7$ & $8.5 \pm 6.0$ \\
\hline TRIMP (AU) & $365.9 \pm 58.2$ & $140.5 \pm 28.6^{*}$ & $148.0 \pm 23.5^{*}$ & $180.3 \pm 22.7 *$ & $137.7 \pm 42.3^{*}$ \\
\hline \multicolumn{6}{|c|}{$\begin{array}{l}\text { Arbitrary units (AU); friendly matches (FM); tactical sessions (TAC); activation sessions (ACTV); } \\
\text { fitness reserves sessions (FIT-RES); fitness sessions (FIT); maximum velocity (MV); total distance } \\
\text { per minute (TD); high intensity distance per minute (HID: }>14.48 \mathrm{Km} \cdot \mathrm{h}^{-1} \text { ); very high intensity } \\
\text { distance per minute (VHID: }>19.8 \mathrm{Km} \cdot \mathrm{h}^{-1} \text { ); sprint distance per minute }\left(\mathrm{SP}:>25.2 \mathrm{Km} \cdot \mathrm{h}^{-1} \text { ); player }\right. \\
\text { load per minute (PL); repeated high-intensity effort per hour (RHIE); distance covered in different } \\
\text { acceleration zones: moderate decelerations distance per hour (DMD; -2 to }-3 \mathrm{~m} \cdot \mathrm{s}^{-2} \text { ) and high } \\
\text { decelerations distance per hour (DHD; }<-3 \mathrm{~m} \cdot \mathrm{s}^{-2} \text { ); moderate accelerations distance per hour (DMA; } \\
2 \text { to } 3 \mathrm{~m} \cdot \mathrm{s}^{-2} \text { ) and high accelerations distance per hour (DHA; }>3 \mathrm{~m} \cdot \mathrm{s}^{-2} \text { ); TRIMP: internal load } \\
\text { calculated by Edward's-TL indicator; * Substantial difference (was set at }>75 \% \text { ) vs. friendly } \\
\text { matches. }\end{array}$} \\
\hline
\end{tabular}


Campos-Vázquez, M.; Castellano, J.; Toscano-Bendala, F. J., \& Owen, A. (2019). Comparison of the physical and physiological demands of friendly matches and different types of preseason training sessions in professional soccer players. RICYDE. Revista internacional de ciencias del deporte. 58(15), 339-352. https://doi.org/10.5232/ricyde2019.05803

Relative to the peak velocity and the distance covered in different velocity zones (Figure 1), substantial differences were observed in all of the variables analysed.

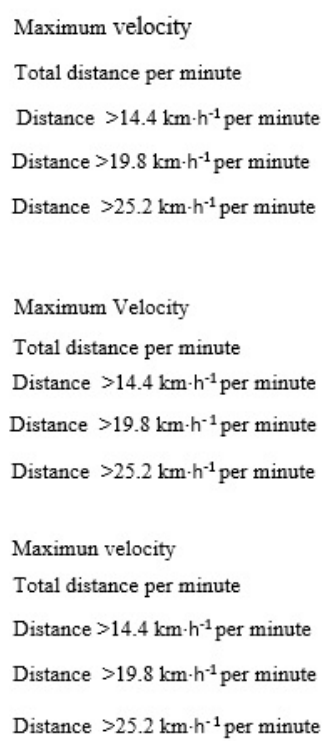

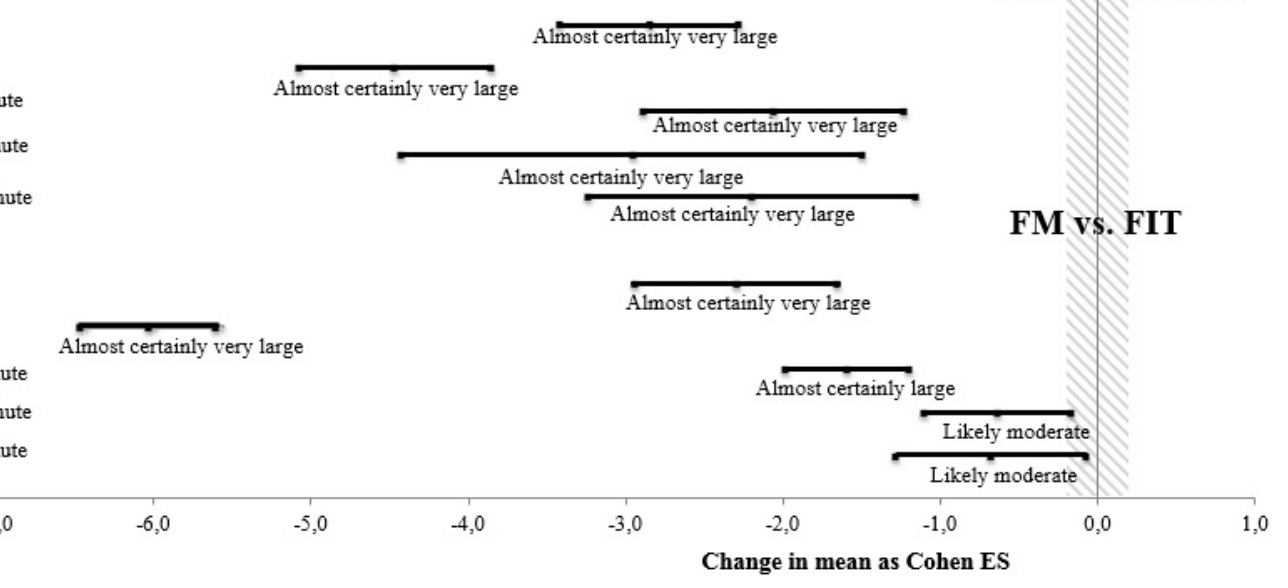

FM vs. TAC

Almost certainly very large

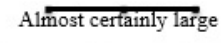

Almost certainly very large

Almost certainly large

Almost certainly very large

Aimost certainly very large

Almost certainly very large

Almost certainly very large Aimost certainly very large

FM vs. FIT-RES

FM vs. ACTV

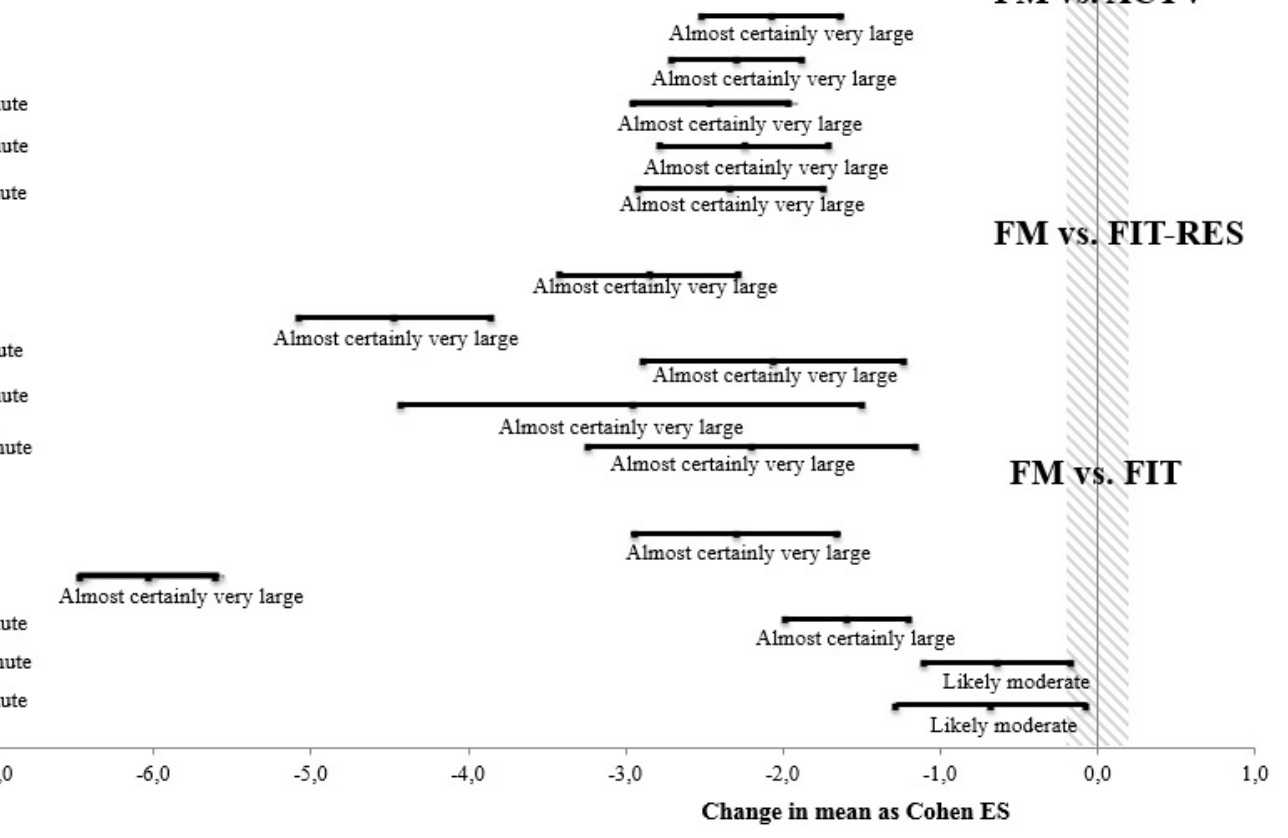

Figure 1. Standardised changes in mean (friendly matches [FMs] and training sessions). TAC: tactical sessions; ACTV: activation sessions; FIT-RES: fitness reserves sessions; FIT: fitness sessions.

Regarding the distance covered in different ranges of acceleration, substantially higher differences were found in the FMs than in the TRs, except for DHA in the ACTV, FIT-RES, and FIT sessions and for the variable DMA in FIT-RES sessions, in which no substantial differences were observed (Figure 2). 
Campos-Vázquez, M.; Castellano, J.; Toscano-Bendala, F. J., \& Owen, A. (2019). Comparison of the physical and physiological demands of friendly matches and different types of preseason training sessions in professional soccer players. RICYDE. Revista internacional de ciencias del deporte. 58(15), 339-352. https://doi.org/10.5232/ricyde2019.05803

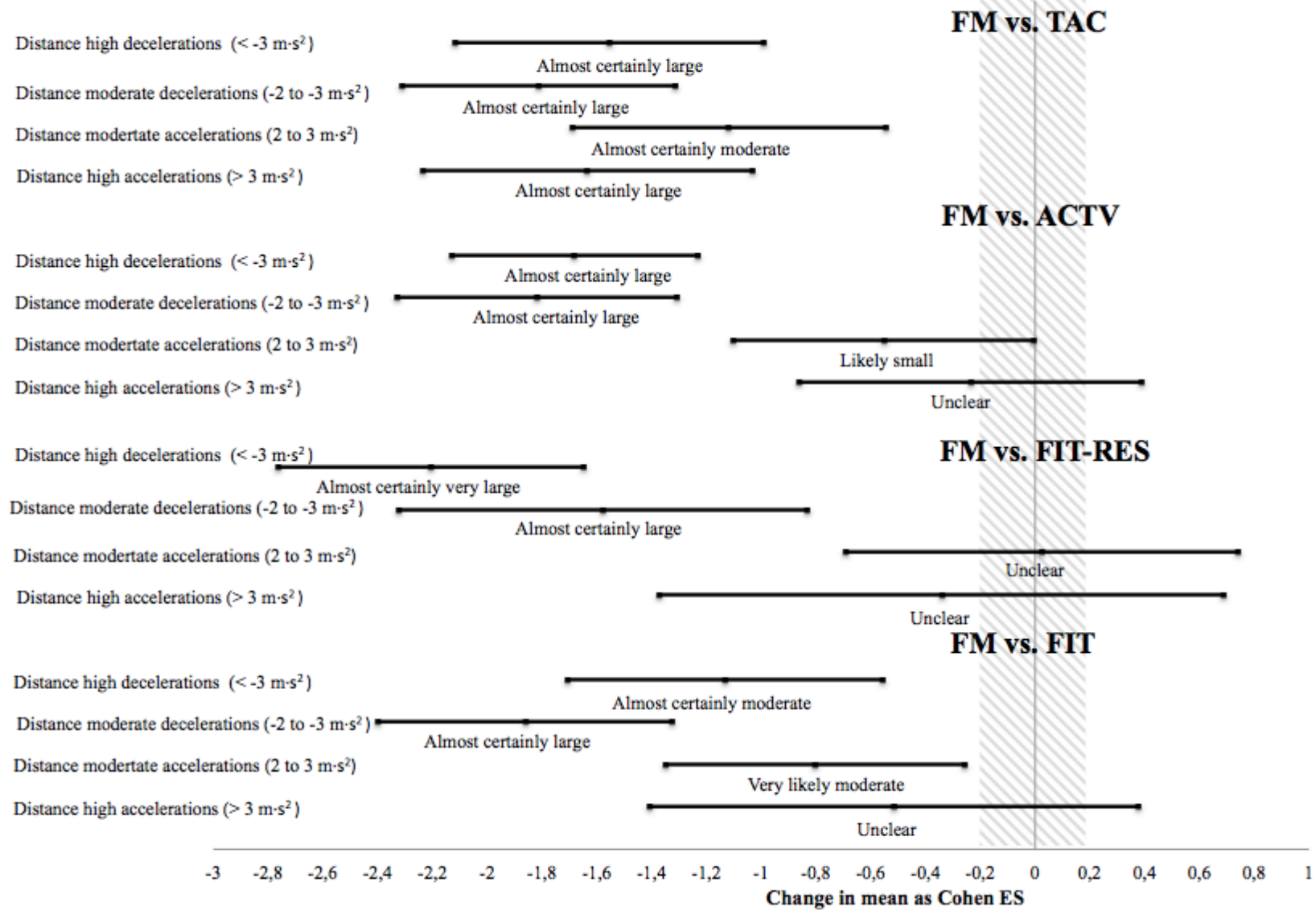

Figure 2. Standardised changes in mean (friendly matches [FMs] and training sessions). Distance covered in different ranges of acceleration. TAC: tactical sessions; ACTV: activation sessions; FIT-RES: fitness reserves sessions; FIT: fitness sessions.

Figure 3 shows the values of PL/min, which are substantially higher in FMs in relation to the TAC sessions ( $\mathrm{ES}=1.77 \pm 0.41$, large), ACTV ( $\mathrm{ES}=2.34 \pm 0.37$, very large), FIT-RES $(1.46 \pm 0.43$, large), and FIT sessions ( $\mathrm{ES}=2.75 \pm 0.43$, very large). Also, the value of this variable during the TAC sessions was substantially higher than ACTV (ES $=0.51 \pm 0.21$, small) and FIT sessions ( $\mathrm{ES}=0.86 \pm 0.28$, moderate). ACTV sessions involved a substantially greater load than the FIT sessions (ES=0.40 \pm 0.17 , small). Finally, in the FIT-RES sessions, the load was substantially greater than in the ACTV sessions ( $\mathrm{ES}=0.64 \pm 0.34$, moderate) and the FIT sessions ( $\mathrm{ES}=1.08 \pm 0.58$, moderate). 
Campos-Vázquez, M.; Castellano, J.; Toscano-Bendala, F. J., \& Owen, A. (2019). Comparison of the physical and physiological demands of friendly matches and different types of preseason training sessions in professional soccer players. RICYDE. Revista internacional de ciencias del deporte. 58(15), 339-352.

https://doi.org/10.5232/ricyde2019.05803

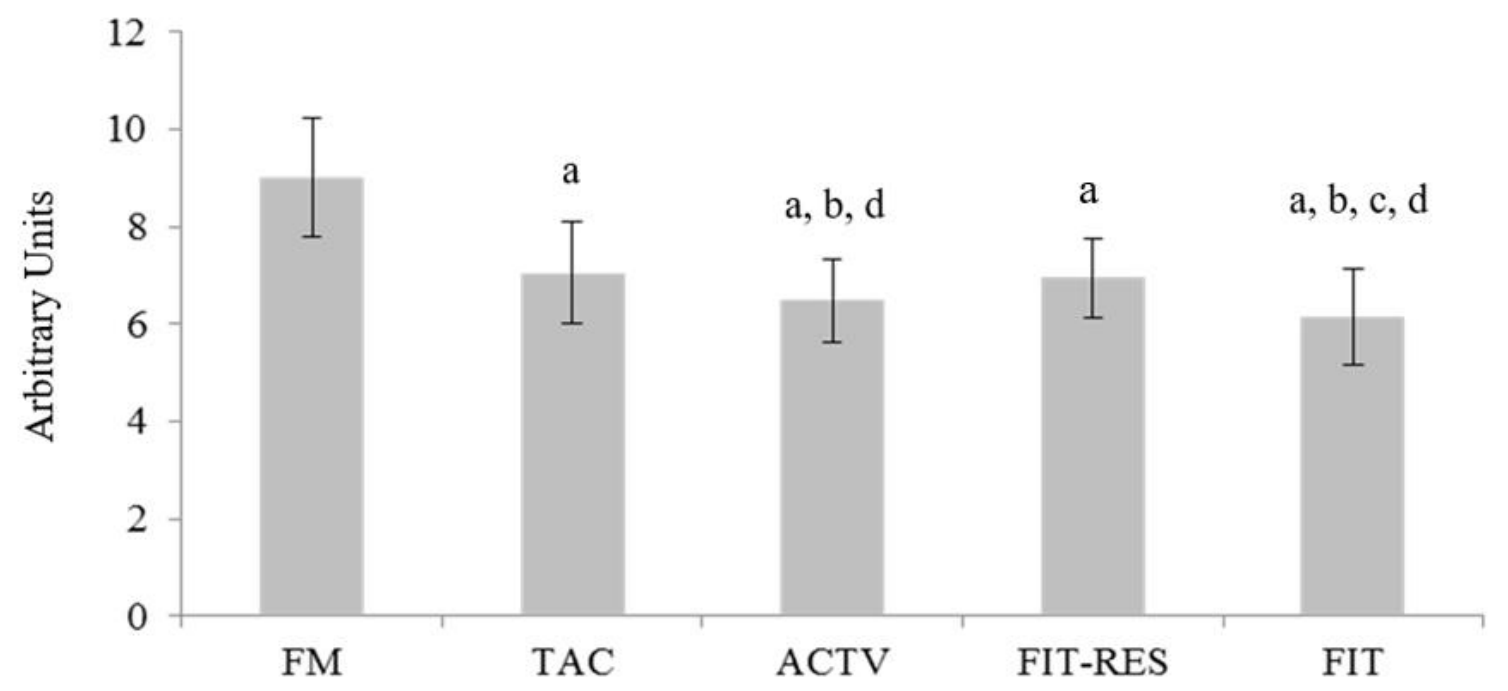

Figure 3. Values of PL/min in friendly matches (FMs) and different types of training sessions; tactical sessions (TAC); activation sessions (ACTV); fitness reserves sessions (FIT-RES); fitness sessions (FIT). a: substantial differences regarding the FM; b: substantial differences regarding TAC; c: substantial differences regarding ACTV; d: substantial differences regarding FIT-RES.

In relation to the number of RHIE per hour of participation, substantially higher differences were found in the FMs than in the TAC ( $\mathrm{ES}=1.67 \pm 0.61$, large), ACTV (ES=1.84 \pm 0.44 , large), FIT-RES (ES $=1.17 \pm 0.64$, moderate), and FIT sessions ( $E S=1.79 \pm 0.43$, large).

Finally, the internal load (Edward's TL) accumulated in the FMs was substantially higher than in the TAC sessions ( $\mathrm{ES}=5.37 \pm 0.52$, very large), ACTV ( $\mathrm{ES}=5.03 \pm 0.57$, very large), FIT-RES (ES=3.82 \pm 0.69 , very large), and FIT sessions ( $E S=5.61 \pm 0.77$, very large). The ACTV sessions demanded substantially higher internal load values than the FIT sessions (ES $=0.62 \pm 0.63$, moderate). Finally, the internal load in the FIT-RES sessions was substantially higher than in the TAC (ES $=1.25 \pm 0.68$, large), ACTV (ES $=1.35 \pm 0.85$, large), and FIT sessions ( $\mathrm{ES}=0.94 \pm 0.60$, moderate).

\section{Discussion}

The aim of this investigation was to compare the physical and physiological demands of FMs with the demands achieved by players in different types of TRs, which are usually performed during a preseason. Coaches usually program FMs during the preseason in order to prepare the players to the effort dynamic usually demanded by official games. The demands of competition could be used as a reference to assess the volume, intensity, and workload of TRs. This is the first investigation comparing TRs and friendly matches, distinguishing different types of TRs, using comparative variables associated with the external and internal load of players. The results showed substantial differences between the FMs and the different types of TRs in the vast majority of the variables analysed, leading to the conclusion that FMs are the most loaded training stimulus performed during the preseason and therefore, players are not stimulated in TRs like in FMs.

For soccer training to be effective, it should be specifically related to the demands required by competitive matches (Reilly, 2005). Few studies have compared the physical demands of training with those of competitive or friendly matches for soccer players (Casamichana \& Castellano, 2011; Scott, et al., 2014). Scott et al. (2014) found significant differences between 
Campos-Vázquez, M.; Castellano, J.; Toscano-Bendala, F. J., \& Owen, A. (2019). Comparison of the physical and physiological demands of friendly matches and different types of preseason training sessions in professional soccer players. RICYDE. Revista internacional de ciencias del deporte. 58(15), 339-352.

https://doi.org/10.5232/ricyde2019.05803

the distances covered by players in the HID, VHID, and SP categories during TRs $(\sim 8.6,2.2$, and $0.3 \mathrm{~m} \cdot \mathrm{min}^{-1}$, respectively) and competitive matches $\left(\sim 27.2,8.7\right.$, and $2.0 \mathrm{~m} \cdot \mathrm{min}^{-1}$, respectively). In our study, with identical velocity thresholds, lower values were obtained during matches $\left(16.8,4.3\right.$, and $0.7 \mathrm{~m} \cdot \mathrm{min}^{-1}$, respectively) than those reflected by Scott et al. (2014). These important differences could be due to the fact that the aforementioned research did not include the warm-up and pauses in the analysis, whereas in our study we decided to include them, as they are part of the game or TR and can give us better guidance on the overall effort and workload. However, some of the types of TRs analysed in our study (FIT) reached relative values of HID, VHID, and SP that were significantly higher $(9.7,3.4$, and 0.5 $\mathrm{m} \cdot \mathrm{min}^{-1}$, respectively) compared to the study of Scott et al. (2014), reflecting differences in training methods and/or in the physical profile between Spanish $1^{\text {st }}$ Division and Australian 1st Division players. The TD in the TRs ranged from $57 \mathrm{~m} \cdot \mathrm{min}^{-1}$ in FIT sessions to $77 \mathrm{~m} \cdot \mathrm{min}^{-}$ ${ }^{1}$ in ACTV sessions. These values were similar to the $68 \mathrm{~m} \cdot \mathrm{min}^{-1}$ reported by Scott et al. (2014), the $80 \mathrm{~m} \cdot \mathrm{min}^{-1}$ by Malone et al. (2015), and the $73 \mathrm{~m} \cdot \mathrm{min}^{-1}$ by Casamichana \& Castellano (2011), who did not differentiate between types of sessions. The lower overall intensity recorded in the FIT sessions could be explained by higher required breaks (where players stand) when performing a high-intensity TR (strength training, HIIT, or SSG). In addition, the TD values for all types of sessions analysed in our research were substantially lower than the $94 \mathrm{~m} \cdot \mathrm{min}^{-1}$ averaged in the FMs. Again, our values in the competition were significantly lower than the $113 \mathrm{~m} \cdot \mathrm{min}^{-1}$ found by Casamichana \& Castellano (2011) in semiprofessional players and the $123 \mathrm{~m} \cdot \mathrm{min}^{-1}$ found by Scott et al. (2014) in professional players. These differences can be explained again by the inclusion of the warm-up and pauses in this investigation.

Regarding the overall load indicator obtained via accelerometry (PL/min), the values reported in this study (Figure 4) were slightly lower in both matches (9 vs. $13.4 \mathrm{AU} \cdot \mathrm{min}^{-1}$ ) and TRs (6.1-7 vs. $\left.8.6 \mathrm{AU} \cdot \mathrm{min}^{-1}\right)$ than those obtained by Casamichana \& Castellano (2011) in semiprofessional players. These authors do not mention whether the warm-up and breaks were included in the analysis, a fact that could explain the differences. However, the MVs achieved in both TRs and games in our study were higher than those reflected by Casamichana \& Castellano (2011): 29.3 vs. $27.1 \mathrm{Km} \cdot \mathrm{h}^{-1}$ in FMs and $24.8-26.6$ vs. $23.5 \mathrm{Km} \cdot \mathrm{h}^{-1}$ in TRs.

The FIT-RES sessions showed the highest values of internal load (Edward's-TL) in all analysed sessions (Table 2). These sessions (performed on the post-match day) are designed to help minimise possible differences in the accumulated load among players who regularly play competitive games and those who do not. Unlike FIT sessions, FIT-RES sessions do not include general of functional strength training, which probably determined a lower ITL in FIT sessions, as previous research have shown in team sports (Lupo, Tessitore, Gasperi \& Gomez, 2017). However, there were substantial differences between FIT-RES sessions and FMs in every variable analysed except in certain variables related to acceleration (DMA, DHA). The inclusion of physical and technical circuits, especially SSG, in these sessions could have conditioned the high demands of acceleration (Castellano \& Casamichana, 2013) and the accumulated internal load (Campos-Vazquez, et al., 2015). However, caution should be applied when monitoring acceleration and deceleration values with GPS technology due to reduced reliability (Buchheit, et al., 2014). On the other hand, variables related to high velocity (MV, HID, VHID, and SP) in FIT-RES sessions showed substantially lower values to the demands of competition. Previous research concluded that in this type of variable related to the intensity, the SSG demands significantly lower values than those demanded by an 11 vs. 11 game on a regulatory field (Casamichana, et al., 2012). Therefore, taking into account the results obtained, we can conclude that, despite the high levels of internal load and 
Campos-Vázquez, M.; Castellano, J.; Toscano-Bendala, F. J., \& Owen, A. (2019). Comparison of the physical and physiological demands of friendly matches and different types of preseason training sessions in professional soccer players. RICYDE. Revista internacional de ciencias del deporte. 58(15), 339-352.

https://doi.org/10.5232/ricyde2019.05803

distance traveled in both zones of acceleration, these sessions do not provide players the values of intensity and load of competitive matches. A possible alternative to alleviate these differences with the competition could be the combination of physical and technical circuits and playing game situations in large spaces ( 8 vs. 8 to $11 \mathrm{vs} .11)$, knowing that as the size and number of players per team increase, the demands become more like the ones in a competitive game (Casamichana \& Castellano, 2010; Owen, Wong, Paul, \& Dellal, 2014).

The TAC and ACTV sessions obtained the highest MV and TD values in all types of sessions (Table 2), although these values were substantially lower than those obtained in FMs. Usually the TAC sessions are held in large spaces (11 vs. 11) in order to assimilate the game model proposed by the coach. However, in these sessions the coach often stops the game to correct certain tactical movements, thereby reducing the intensity of the task and therefore the session, furthering the TD values from those in competitive matches. Meanwhile, the ACTV sessions are conducted prior to the match day. During the competitive season, coaches deliberately reduce the training load in these sessions (Malone, et al., 2015) so that the players approach the game at optimum fitness levels. Our results did not show the reduction of workload in the ACTV session. This may reflect the low priority given by coaches to the preparation of players before FMs in the preseason and could have negative consequences in the accumulated fatigue. Therefore, it could cause a possible increase in injuries suffered during this period (Ekstrand, Hagglund, \& Walden, 2011).

\section{Conclusions}

The conclusion of this study was that FMs were the most loaded stimulus performed during the preseason. The vast majority of internal and external load variables analysed obtained higher values in FMs than in the different types of sessions performed. These results highlight the importance to play FMs during the preseason. Although potentially, a low volume of high-intensity efforts made during the TRs combined with possible improvements achieved in matches could be enough to reach the 'fitness levels' required by players (Scott, et al., 2014), in the preseason coaches should provide their players with a sufficient volume of minutes in FMs, to achieve the desired improvements in fitness (Campos-Vazquez, Toscano-Bendala, Mora-Ferrera, \& Suarez-Arrones, 2017). To do this, proper periodisation of training stimuli between matches is required (Impellizzeri, Rampinini, Coutts, Sassi, \& Marcora, 2004), intensifying certain tasks and sessions in specific phases of the weekly microcycle and mesocycle (preseason). To conclude, it can be suggested that FMs produce the highest loaded training stimulus when compared across most metrics used for training analysis comparisons across the preseason period. Training sessions in general were not able to simulate intensities occurring during FMs. These findings reflect the inherent nature of the TRs conducted in soccer the field in team sports, where most low-intensity activity can be justified by the amount of time that coaches dedicate to explaining the tasks to players or breaks between sets of exercises and/or hydration. Therefore, increasing the demand in certain TRs by including tasks (analytical or based on game situations) with the potential to increase the volume of activity at high intensity, and thus raising both physical and physiological stress on players during TRs, could be necessary for players who do not have an adequate participation in FMs during the preseason. Furthermore, and as a result of this study, the use of friendly matches within the pre-season phase of the season should warrant additional care when planned between high intensity and high volume training loads. 
Campos-Vázquez, M.; Castellano, J.; Toscano-Bendala, F. J., \& Owen, A. (2019). Comparison of the physical and physiological demands of friendly matches and different types of preseason training sessions in professional soccer players. RICYDE. Revista internacional de ciencias del deporte. 58(15), 339-352.

https://doi.org/10.5232/ricyde2019.05803

\section{References}

Akenhead, R.; French, D.; Thompson, K. G., \& Hayes, P. R. (2014). The acceleration dependent validity and reliability of $10 \mathrm{~Hz}$ GPS. Journal of Science and Medicine in Sport, 17(5), 562-566.

https://doi.org/10.1016/j.jsams.2013.08.005

Aughey, R. J. (2011). Increased high-intensity activity in elite Australian football finals matches. International Journal of Sports Physiology and Performance, 6(3), 367-379.

Batterham, A. M., \& Hopkins, W. G. (2006). Making meaningful inferences about magnitudes. International Journal of Sports Physiology and Performance, 1(1), 50-57.

Buchheit, M. (2008). The 30-15 intermittent fitness test: accuracy for individualizing interval training of young intermittent sport players. Journal of Strength and Conditioning Research, 22(2), 365-374. https://doi.org/10.1519/JSC.0b013e3181635b2e

Buchheit, M., Al Haddad, H., Simpson, B.M., Palazzi, D., Bourdon, P.C., Di Salvo, V., \& Mendez-Villanueva, A. (2014). Monitoring Accelerations With GPS in Football: Time to Slow Down? International Journal of Sports Physiology and Performance, 9(3), 442445. https://doi.org/10.1123/ijspp.2013-0187

Bush, M.; Barnes, C.; Archer, D. T.; Hogg, B., \& Bradley, P. S. (2015). Evolution of match performance parameters for various playing positions in the English Premier League. Human Movement Science, 39, 1-11.

https://doi.org/10.1016/j.humov.2014.10.003

Campos-Vazquez, M. A.; Mendez-Villanueva, A.; Gonzalez-Jurado, J. A.; Leon-Prados, J. A.; Santalla, A., \& Suarez-Arrones, L. (2015). Relationships between rating-ofperceived-exertion- and heart-rate-derived internal training load in professional soccer players: a comparison of on-field integrated training sessions. International Journal of Sports Physiology and Performance, 10(5), 587-592.

https://doi.org/10.1123/ijspp.2014-0294

Casamichana, D., \& Castellano, J. (2010). Time-motion, heart rate, perceptual and motor behaviour demands in small-sides soccer games: effects of pitch size. Journal of Sports Sciences, 28(14), 1615-1623.

https://doi.org/10.1080/02640414.2010.521168

Campos-Vazquez, M. A.; Toscano-Bendala, F. J.; Mora-Ferrera, J. C., \& Suarez-Arrones, L. J. (2017). Relationship Between Internal Load Indicators and Changes on Intermittent Performance After the Preseason in Professional Soccer Players. Journal of Strength and Conditioning Research, 31(6), 1477-1485.

https://doi.org/10.1519/JSC.0000000000001613

Campos-Vazquez, M. A., \& Toscano-Bendala, F. J. (2018). Comparación de la percepción subjetiva del esfuerzo entre partidos amistosos y diferentes tipos de sesión en futbolistas profesionales. Retos, 34, 66-70.

Casamichana, D., \& Castellano, J. (2011). Demandas físicas en jugadores semiprofesionales de fútbol: ¿se entrena igual que se compite? Revista Cultura, Ciencia y Deporte, 17(6), 121-127.

Casamichana, D.; Castellano, J., \& Castagna, C. (2012). Comparing the physical demands of friendly matches and small-sided games in semiprofessional soccer players. Journal of Strength and Conditioning Research, 26(3), 837-843.

https://doi.org/10.1519/JSC.0b013e31822a61cf

Castellano, J., \& Casamichana, D. (2013). Differences in the number of accelerations between small-sided games and friendly matches in soccer. Journal of Sports Science and Medicine, 12(1), 209-210. 
Campos-Vázquez, M.; Castellano, J.; Toscano-Bendala, F. J., \& Owen, A. (2019). Comparison of the physical and physiological demands of friendly matches and different types of preseason training sessions in professional soccer players. RICYDE. Revista internacional de ciencias del deporte. 58(15), 339-352.

https://doi.org/10.5232/ricyde2019.05803

Castellano, J.; Casamichana, D.; Calleja-Gonzalez, J.; Roman, J. S., \& Ostojic, S. M. (2011). Reliability and Accuracy of $10 \mathrm{~Hz}$ GPS Devices for Short-Distance Exercise. Journal of Sports Science and Medicine, 10(1), 233-234.

Coutinho, D.; Goncalves, B.; Figueira, B.; Abade, E.; Marcelino, R., \& Sampaio, J. (2015). Typical weekly workload of under 15, under 17, and under 19 elite Portuguese football players. Journal of Sports Sciences, 33(12), 1229-1237. https://doi.org/10.1080/02640414.2015.1022575

Desgorces, F. D.; Senegas, X.; Garcia, J.; Decker, L., \& Noirez, P. (2007). Methods to quantify intermittent exercises. Applied Physiololgy Nutrition and Metabolism, 32(4), 762-769. https://doi.org/10.1139/H07-037

Di Salvo, V.; Baron, R.; Tschan, H.; Calderon Montero, F. J.; Bachl, N., \& Pigozzi, F. (2007). Performance characteristics according to playing position in elite soccer. International Journal of Sports Medicine, 28(3), 222-227. https://doi.org/10.1055/s-2006-924294

Di Salvo, V.; Gregson, W.; Atkinson, G.; Tordoff, P., \& Drust, B. (2009). Analysis of high intensity activity in Premier League soccer. International Journal of Sports Medicine, 30(3), 205-212.

https://doi.org/10.1055/s-0028-1105950

Edwards, S. (1993). High performance training and racing. Sacramento: Fleet Feet Press.

Ekstrand, J.; Hagglund, M., \& Walden, M. (2011). Injury incidence and injury patterns in professional football: the UEFA injury study. British Journal of Sports Medicine, 45(7), 553-558. https://doi.org/10.1136/bjsm.2009.060582

Hopkins, W. G. (2006). Spreadsheets for analysis of controlled trials, with adjustment for a subjet characteristics. SportsScience, 10, 46-50.

Hopkins, W. G.; Marshall, S. W.; Batterham, A. M., \& Hanin, J. (2009). Progressive statistics for studies in sports medicine and exercise science. Medicine and Science in Sports and Exercise, 41(1), 3-13.

https://doi.org/10.1249/MSS.0b013e31818cb278

Iaia, F. M.; Rampinini, E., \& Bangsbo, J. (2009). High-intensity training in football. International Journal of Sports Physiology and Performance, 4(3), 291-306.

Impellizzeri, F. M.; Rampinini, E.; Coutts, A. J., Sassi, A., \& Marcora, S. M. (2004). Use of RPE-based training load in soccer. Medicine and Science in Sports and Exercise, 36(6), 1042-1047.

https://doi.org/10.1249/01.MSS.0000128199.23901.2F

Jeong, T. S.; Reilly, T.; Morton, J.; Bae, S. W., \& Drust, B. (2011). Quantification of the physiological loading of one week of "pre-season" and one week of "in-season" training in professional soccer players. Journal of Sports Sciences, 29(11), 1161-1166. https://doi.org/10.1080/02640414.2011.583671

Lago-Peñas, C.; Lago-Ballesteros, J.; Dellal, A., \& Gomez, M. (2010). Game-Related Statistics that Discriminated Winning, Drawing and Losing Teams from the Spanish Soccer League. Journal of Sports Science and Medicine, 9(2), 288-293.

Lupo, C., Tessitore, A., Gasperi, L., \& Gomez, M. (2017). Session-RPE for quantifying the load of different youth basketball training sessions. Biology of Sport, 34(1), 11-17. https://doi.org/10.5114/biolsport.2017.63381

Malone, J. J.; Di Michele, R.; Morgans, R.; Burgess, D.; Morton, J. P., \& Drust, B. (2015). Seasonal training-load quantification in elite English premier league soccer players. International Journal of Sports Physiology and Performance, 10(4), 489-497. https://doi.org/10.1123/ijspp.2014-0352 
Campos-Vázquez, M.; Castellano, J.; Toscano-Bendala, F. J., \& Owen, A. (2019). Comparison of the physical and physiological demands of friendly matches and different types of preseason training sessions in professional soccer players. RICYDE. Revista internacional de ciencias del deporte. 58(15), 339-352.

https://doi.org/10.5232/ricyde2019.05803

Montgomery, P. G.; Pyne, D. B., \& Minahan, C. L. (2010). The physical and physiological demands of basketball training and competition. International Journal of Sports Physiology and Performance, 5(1), 75-86.

Osgnach, C.; Poser, S.; Bernardini, R.; Rinaldo, R., \& di Prampero, P. E. (2010). Energy cost and metabolic power in elite soccer: a new match analysis approach. Medicine and Science in Sports and Exercise, 42(1), 170-178.

https://doi.org/10.1249/MSS.0b013e3181ae5cfd

Owen, A.; Djaoui, L.; Newton, M.; Malone, S., \& Mendes, B. (2017). A contemporary multi-modal mechanical approach to training monitoring in elite professional soccer Science and medicine in football, 1(3), 216-221.

Owen, A. L.; Wong, D. P.; Paul, D., \& Dellal, A. (2014). Physical and technical comparisons between various-sided games within professional soccer. International Journal of Sports Medicine, 35(4), 286-292.

https://doi.org/10.1055/s-0033-1351333

Rampinini, E.; Coutts, A. J.; Castagna, C.; Sassi, R., \& Impellizzeri, F. M. (2007). Variation in top level soccer match performance International Journal of Sports Medicine, 28(12), 1018-1024. https://doi.org/10.1055/s-2007-965158

Reilly, T. (2005). Training specificity for soccer. International Journal of Applied Sports Sciences, 17(2), 17-25.

Sampaio, J.; Abrantes, C., \& Leite, N. (2009). Power, hearte rate and perceived exertion responses to $3 \times 3$ and $4 \times 4$ basketball small-sided games. Revista de Psicología del Deporte, 18, 443-467.

Scott, B. R.; Lockie, R. G.; Davies, S. J. G.; Clark, A.; Lynch, D., \& de Jong, X. A. (2014). The physical demands of professional soccer players during in -season fieldbased training and match-play. Journal of Australian Strength and Conditioning, 22(4), 7-15.

Scott, B. R.; Lockie, R. G.; Knight, T. J.; Clark, A. C., \& Janse de Jonge, X. A. (2013). A comparison of methods to quantify the in-season training load of professional soccer players. International Journal of Sports Physiology and Performance, 8(2), 195-202.

Silva, J. R.; Nassis, G. P., \& Rebelo, A. (2015). Strength training in soccer with a specific focus on highly trained players. Sports Medicine Open, 1(1), 17. https://doi.org/10.1186/s40798-015-0006-z

Suarez-Arrones, L.; Arenas, C.; Lopez, G.; Requena, B.; Terrill, O., \& Mendez-Villanueva, A. (2014). Positional differences in match running performance and physical collisions in men rugby sevens. International Journal of Sports Physiology and Performance, 9(2), 316-323.

https://doi.org/10.1123/ijspp.2013-0069

Suarez-Arrones, L.; Torreno, N.; Requena, B.; Saez De Villarreal, E.; Casamichana, D.; Barbero-Alvarez, J. C., \& Munguia-Izquierdo, D. (2015). Match-play activity profile in professional soccer players during official games and the relationship between external and internal load. Journal of Sports Medicine and Physical Fitness, 55(12), 1417-1422.

Varley, M. C.; Elias, G. P., \& Aughey, R. J. (2012). Current match-analysis techniques' underestimation of intense periods of high-velocity running. International Journal of Sports Physiology and Performance, 7(2), 183-185.

Varley, M. C.; Fairweather, I. H., \& Aughey, R. J. (2012). Validity and reliability of GPS for measuring instantaneous velocity during acceleration, deceleration, and constant motion. Journal of Sports Sciences, 30(2), 121-127.

https://doi.org/10.1080/02640414.2011.627941 